\title{
Analisis Pengaruh Pendidikan Karakter, Status Sosial dan Jiwa Humanis terhadap Budaya Keselamatan dan Kesehatan Kerja (Studi Pada Universitas Pamulang)
}

\section{Analysis of the Influence of Character Education, Social Status and Humanist Spirit on Occupational Health and Safety Culture (Study at Pamulang University)}

\author{
Rahmi Hermawati *, Rima Handayani \& Eni Puji Astuti \\ Universitas Pamulang, Banten, Indonesia
}

Diterima : 02 Oktober 2020 ; Direview : 13 Oktober 2020 ; Disetujui : 18 Oktober 2020

*Coresponding Email : rahmi herma@yahoo.com

\begin{abstract}
Abstrak
Penelitian ini bertujuan untuk mengetahui pengaruh pendidikan karakter dan status sosial terhadap budaya Budaya Keselamatan dan Kesehatan Kerja (K3) (studi pada Universitas Pamulang). Penelitian ini bersifat penelitian kuantitatif kausal (sebab akibat dengan mengolah data angka), menggunakan metode survei pengumpulan data melalui penyebaran kuesioner kepada mahasiswa Universitas Pamulang Prodi Manajemen, dengan penentuan sampel menggunakan rumus slovin. Analisis data menggunakan analisis uji validitas, uji reliabilitas, uji asumsi klasik, analisis regresi berganda, analisis koefisien korelasi, analisis koefisien determinasi, uji t, dan uji F. Data yang didapat dari responden diolah dengan menggunakan SPSS 26. Hasil penelitian menunjukkan adanya pengaruh antara pendidikan karakter, status sosial dan jiwa humanis terhadap budaya K3. Berdasarkan hasil penelitian, maka kesimpulan hasil penelitian adalah sebagai berikut: hasil yang pendidikan karakter $\left(\mathrm{X}_{1}\right)$, status sosial $\left(\mathrm{X}_{2}\right)$ dan jiwa humanis $\left(\mathrm{X}_{2}\right)$ bersama berpengaruh sangat signifikan terhadap budaya K3 (Keselamatan dan Kesehatan Kerja) mahasiswa di Prodi Manajemen Universitas Pamulang.

Kata Kunci : Pendidikan Karakter, Status Sosial, Jiwa Humanis , Budaya K3
\end{abstract}

\begin{abstract}
This study aims to determine the effect of character education and social status on the culture of Occupational Safety and Health (K3) (a study at Pamulang University). This research is a causal quantitative research (cause and effect by processing numerical data), using a survey method of data collection through distributing questionnaires to Pamulang University students of Management Study Program, by determining the sample using the Slovin formula. Data analysis used validity test analysis, reliability test, classical assumption test, multiple regression analysis, correlation coefficient analysis, determination coefficient analysis, $t$ test, and $F$ test. Data obtained from respondents were processed using SPSS 26. The results showed that there was an influence between character education, social status and a humanist spirit towards K3 culture. Based on the results of the study, the conclusions of the research results are as follows: the results of character education (X1), social status (X2) and a humanist spirit (X2) together have a very significant effect on the K3 (Occupational Health and Safety) culture of students in the Management Study Program at Pamulang University. Keywords: Character Education, Social Status, Humanist Spirit, K3 Culture
\end{abstract}

How to cite: Hermawati, R. Handayani, R. \& Astuti, E.P. (2020), Analisis Pengaruh Pendidikan Karakter, Status Sosial dan Jiwa Humanis terhadap Budaya Keselamatan dan Kesehatan Kerja (Studi Pada Universitas Pamulang) 3(2) 610-619 
Rahmi Hermawati, Rima Handayani \& Eni Puji Astuti, Analisis Pengaruh Pendidikan Karakter, Status

\section{PENDAHULUAN}

Keselamatan dan Kesehatan Kerja (K3) merupakan hal utama yang harus selalu diterapkan oleh siapapun di lingkungan manapun. Kenyataannya kurangnya kepedulian orang terhadap Keselamatan dan Kesehatan Kerja (K3) masih terus berlanjut hingga saat ini. Dalam hal ini, Kemenakertrans sudah mempunyai perhatian penuh terhadap pekerja yang ada di Indonesia, dilihat dengan adanya visi kemenakertrans adalah "Indonesia Budaya K3 di tahun 2015". Ini terlihat jelas bahwa ada perhatian khusus terhadap peningkatan K3 dengan melakukan pembinaan kepada perusahaan untuk melaksanakan K3. Ini dilakukan karena pelaksanaan K3 masih belum maksimal ditandai dengan masih tingginya angka kecelakaan yang terjadi di Indonesia. Berdasarkan data BPJS Ketenagakerjaan, pada tahun 2018 telah terjadi kecelakaan yang berada ditempat kerja sebanyak 114.148 kasus. Sementara pada tahun 2019, hanya 77.295 kasus saja atau turun 33,05\%. Meskipun jumlah kecelakaan kerja pada tahun lalu mengalami penurunan dari periode sebelumnya masalah kecelakaan kerja masih menjadi tantangan di bidang ketenagakerjaan.

Budaya Keselamatan dan Kesehatan Kerja (K3) belum mendapat banyak perhatian di lingkungan kampus atau universitas. Padahal K3 merupakan hal utama yang harus selalu diterapkan oleh siapapun di lingkungan manapun. Lingkungan kampus atau tempat perkuliahan juga merupakan titik vital dimana orang yang berada dikawasan tersebut diharapkan bisa melakukan penerapan terhadap manajemen K3. Tidak menutup kemungkinan bahwa lingkungan perkuliahan juga memiliki peluang akan terjadinya kecelakaan. Kecelakaan mungkin bisa terjadi di ruangan Laboratorium dimana mahasiswa biasa melakukan kegiatan praktikum, kecelakaan juga bisa terjadi bagi staf perkuliahan ataupun bagi dosen sekalipun (Mora, Z., et al., 2020; Latief, et al., 2019).

Pelaksanaan program K3 di lingkungan kampus sudah selayaknya dilakukan sejak dini agar menjadi suatu kebiasaan pada saat mereka bekerja suatu hari nanti. Untuk menanamkan kesadaran akan K3 diperlukan suatu karakter (Latief, et al., 2018; Syardiansah, et al., 2020; Haryati, et al., 2019). Karakter adalah nilai-nilai yang khas, baik watak, akhlak atau kepribadian seseorang yang terbentuk dari hasil internalisasi berbagai kebijakan yang diyakini dan dipergunakan sebagai cara pandang, berpikir, bersikap, berucap dan bertingkah laku dalam kehidupan sehari-hari. Dari karakter yang ada pada diri manusia, terdapat nilai-nilai karakter berdasarkan budaya dan bangsa seperti religious, jujur, toleransi, disiplin, kerja keras, kreatif, mandiri, demokratis, rasa ingin tahu, semangat kebangsaan, cinta tanah air, menghargai prestasi, bersahabat atau komunikatif, cinta damai, gemar membaca, peduli lingkungan, peduli sosial, dan tanggung jawab. Saat ini sudah waktunya kampus menggalakkan pendidikan karakter secara kongkrit bagi mahasiswanya (Nainggolan \& Parulian, 2018; Amelia, 2016).

Pendidikan karakter yang idealnya ditanamkan sejak dini di lembaga pendidikan dasar dan menengah, seharusnya lebih ditingkatkan pada jenjang pendidikan tinggi. Sebab peserta didik di lingkungan kampus mempunyai kepentingan langsung dan praktis terhadap karakter-karakter positif, serta lebih dekat untk terjun dalam kehidupan riil di masyarakat. Dengan demikian karakter-karakter positif bagi mahasiswa merupakan keniscayaan dan kebutuhan yang mendesak.

Status sosial merupakan suatu kedudukan sosial seseorang di masyarakat yang mampu didapat dengan sendirinya (otomatis) melalui usaha ataupun karena pemberian. Interaksi sosial akan mendorong individu untuk bisa mencapai status sosial yang lebih tinggi. Status sosial yang lebih tinggi akan berpengaruh pula pada sikap dan rasa penghargaan yang tinggi dari masyarakat. Oleh sebab itu, setiap orang akan berusaha untuk mencapai status sosial yang lebih tinggi. Status sosial adalah kedudukan sosial seseorang atau individu dalam kelompok masyarakat. Dengan demikian, seseorang dapat memiliki beberapa status karena ikut serta dalam berbagai kelompok dalam kehidupan bermasyarakat. Status yang dimiliki oleh seseorang akan menentukan derajat, kewajiban, dan tanggung jawab dalam kelompoknya.

Era Globalisasi saat ini menimbulkan berbagai persoalan, misalnya bebasnya kontak budaya lokal dengan budaya asing tanpa batas, tercabutnya nilai-nilai moral spiritual, persaingan bebas antar bangsa, kemajuan teknologi tanpa diimbangi sikap moral, kurang peduli dengan lingkungan 色 $h$ http://mahesainstitute.web.id/ojs2/index.php/jehss 
sekitar dan sebagainya. Semua orang pada zaman ini dituntut memiliki sikap cerdas dalam memilah dan memilih dampak globalisasi (Indrawan, Wijoyo, Suherman, et al., 2020). Pendidikan sebagai basis pembentukkan perilaku, proses pembudayaan, dan penanaman nilai diharapkan dapat memberikan informasi yang komprehensif tentang sisi positif dan sisi negatif arus globalisasi. Bagaimanakah peran pendidikan humanis dalam menyikapi persoalan di atas? Konsep pendidikan ini sebagai bentuk pendidikan yang menekankan pada pembudayaan sikap saling menghargai keberagaman atau keanekaragaman budaya, ras, suku, agama dan sikap kepatuhan terhadap perintah Tuhan YME akan dapat mewujudkan nilai-nilai moral-spiritual, seperti: humanis-religius. Humanis adalah sikap yang mengedepankan sisi-sisi kemanusiaan. Sikap humanis mengedepankan sikap memanusiakan manusia dalam konteks menghadapi perbedaan dalam keberagaman(Indrawan, Wijoyo, \& Awom, 2020).

Hal ini tentulah perlu mendapatkan perhatian khusus agar kesadaran K3 mulai ditanamkan sebelum mereka memasuki dunia kerja. Terkait dengan hal tersebut di atas penulis melihat adanya suatu fenomena di kalangan kampus Unpam khususnya di prodi manajemen. Jumlah mahasiswa yang sangat banyak dibandingkan dengan prodi-prodi lain, temtunya mempunyai karakter, status sosial dan jiwa humanis yang beragam. Mereka kurang peduli akan kebersihan, kesehatan dan keselamatan pada lingkungan. Mereka kurang kesadaran untuk membuang sampah ke tempat sampah yang sudah disediakan. Mereka merasa nyaman saja berada di ruang kelas yang kotor, dan tidak bergerak membuang sampah pada tempatnya. Botol-botol minuman dan sampah makanan mereka letakkan di bawah kursi dan ketika pulang tidaka ada usaha untuk membuangnya, seolaholah kebersihan adalah tugas dari office boy.

Setelah perkuliahan selesai, nampak sampah-sampah berserakan di ruang kelas dan di samping tempat sampah yang sudah menumpuk. Jika dijalan ditemukan sampah tisu, mereka tidak tergerak untuk mengambilnya dan membuangnya ke tong sampah. Begitu pula kesadaran akan keselamatan pada diri sendiri, seperti menggunakan hp pada saat berjalan di tangga, tidak menggunakan helm pada saat mengendarai motor.

Kurangnya kesadaran K3 ini tentunya dipengaruhi oleh berbagi faktor, seperti pendidikan karaktek. Salah satu karakter yang harus diterapkan sejak dini kepada anak adalah karakter cinta lingkungan. Peduli lingkungan merupakan sikap dan tindakan yang selalu berupaya mencegah kerusakan lingkungan alam di sekitarnya dan pengembangkan upayaupaya untuk memperbaiki kerusakan alam yang sudah terjadi. Karakter peduli lingkungan alam merupakan sikap yang ditunjukkan dengan perbuatan menjaga lingkungan alam sekitarnya. Sikap ini juga ditunjukan dengan tindakan memperbaiki kerusakan lingkungan yang terjadi. (Indrawan, Wijoyo, Winditya, et al., 2020).

Selain faktor pendidikan karakter, kesadaran K3 juga dipengaruhi oleh faktor status sosial. Hubungan kepedulian lingkungan dan status sosial berdasarkan persspektif negara berkembang akan selalu menarik untuk dibahas, ada hal-hal sifatmya kontekstual sehingga berbeda dengan riset yang dilakukan di negara maju. Apabila merujuk ke asumsi-asumsi terdahulu, banyak pertentangan mengenai penagaruh latar belakang sosial seseorang terhadap kepedulian lingkungan. Asumsi lama mengatakan bahwa kepedulian lingkungan merupakan bagian dari nilainilai post-materialist sehingga hanya dimiliki oleh kalangan atas. Jika asumsi tersebut ditarik pada tingkatan makro, maka kepedulian lingkungan negara maju akan lebih tinggi dibandingkan kepedulian di negara berkembang karena nilai-nilai post-materialist seolah-olah lebih dahulu berkembang di sana.

Asumsi lama yang mengidentikkan kepedulian lingkungan dengan kalangan atas berawal dari teori yang diungkapkan oleh Maslow (1970) mengenai hierarchy of needs. Dia berasumsi bahwa kepedulian terhadap kualitas lingkungan merupakan sesuatu yang mewah dan hanya bisa dinikmati setelah kebutuhan dasar terpenuhi, seperti makanan, tempat tinggal, dan keamanan finasial (Wijoyo et al., 2020).

Fenomena ini menjadi bahan yang akan di bahas oleh peneliti, mengingat Universitas Pamulang merupakan universitas yang sangat beragam baik suku, agama, dan status sosialnya, 
Rahmi Hermawati, Rima Handayani \& Eni Puji Astuti, Analisis Pengaruh Pendidikan Karakter, Status

Berdasarkan hasil distribusi kuesioner, diperoleh data tingkat status sosial keluarga sebagai berikut.

Tabel 1 Data Penghasilan Orang Tua

\begin{tabular}{|l|r|}
\hline Range Penghasilan Orang Tua & \multicolumn{1}{|c|}{ Total } \\
\hline$<5$ juta & 340 \\
\hline$>15$ juta & 1 \\
\hline $11-15$ juta & 7 \\
\hline $6-10$ juta & 45 \\
\hline Grand Total & 393 \\
\hline
\end{tabular}

Sumber: Hasil distribusi kuesioner google form Juni 2020

Data Pendidikan Orang Tua

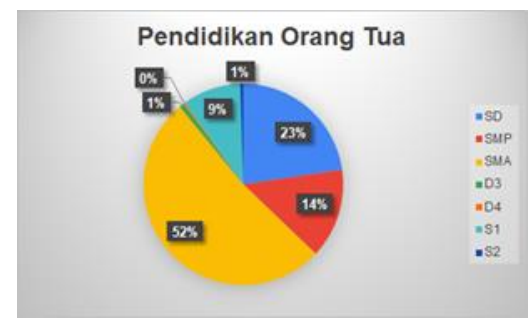

Gambar 1: Diagram Pendidikan Orang Tua

Sumber: Hasil distribusi kuesioner google form Juni 2020

Tabel 2 Data Pekerjaan Orang Tua

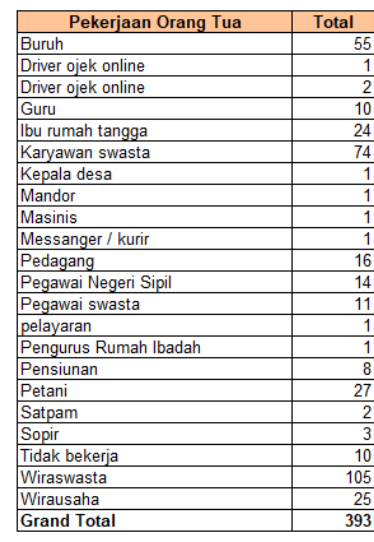

Sumber: Hasil distribusi kuesioner google form Juni 2020

Tabel 1 dan 2, serta grafik 1, menunjukkan bahwa status sosial mahasiswa sangat beragam, tercermin pada data penghasilan orang tua yang sebagian besar di bawah 5 juta, pendidikan orang tua rata-rata SMA dan pekerjaan orang tua adalah sebagian karyawan swasta dan buruh.

Fenomena ini lain terhadap budaya K3 yang ingin diteliti adalah jiwa humanis. Menurutnya humanisme adalah paham filsafat yang menjunjung tinggi nilai dan kedudukan manusia serta menjadikannya sebagai kriteria segala sesuatu. Konsep utama dari pemikiran pendidikan humanistik menurut Mangunwijaya (Winardi, 2006)adalah "menghormati harkat dan martabat manusia". Hal mendasar dalam pendidikan humanistik adalah keinginan untuk mewujudkan lingkungan belajar yang menjadikan peserta didik terbebas dari kompetisi yang hebat, kedisiplinan yang tinggi, dan takut gagal. 
Terkait dengan visi misi Universitas Pamulang yaitu menjadi universitas peringkat 40 besar pada tingkat nasional yang dilandasi oleh nilai humanis dan religius pada tahun 2024, maka penulis tertarik melihat fenomena tentang peduli lingkungan salah satu satunya adalah kesadaran terhadap budaya K3, Berdasarkan pengamatan, kesadaran diri mahasiswa masih belum terlihat, mereka tidak merasa bahwa menjaga kebersihan adalah menjadi suatu habit atau kebiasaan yang harusnya sudah melekat pada diri mereka. Kesadaran membuang sampah pada tempatnya, mengambil sampah tisu di lorong jika mereka lihat di depan mata mereka, dan membuang pembalut atau tisu di toilet tidak pada tempatnya. Begitu pula kesadaran akan budaya memakai helm pada saat mengendarai motor, memakai masker, pelindung badan (jaket), dan sambil berjalan masih menggunakan handphone. Hal ini tentunya berbahaya bagi kesehatan dan keselamatan mereka.

Berdasarkan pengamatan dan fenomena tersebut di atas, maka penulis tertarik untuk meneliti tentang "Analisis Pengaruh Pendidikan Karakter, Status Sosial dan Jiwa Humanis terhadap Budaya K3 (Studi pada Universitas Pamulang).

\section{METODE PENELITIAN}

Penelitian ini bersifat penelitian kuantitatif kausal ( sebab akibat dengan mengolah data angka ), menggunakan metode survei dengan mengumpulkan data melalui penyebaran kuesioner kepada mahasiswa Universitas Pamulang Prodi Manajemen, yang hasilnya kemudian diolah melalui program SPSS Versi 26.00 tahun 2020, untuk mengetahui pengaruh antara variabel pendidikan karakter, status sosial, jiwa humanis dan pendidikan karakter terhadap hasil belajar mahasiswa Universitas Pamulang. Variabel yang akan diteliti adalah pendidikan karakter ( $\left.\mathrm{X}_{1}\right)$, status sosial $\left(\mathrm{X}_{2}\right)$, jiwa humanis $\left(\mathrm{X}_{3}\right)$,), dan budaya $\mathrm{K} 3(\mathrm{Y})$.

\section{HASIL DAN PEMBAHASAN}

\section{a. Uji Asumsi Klasik}

1. Uji Normalitas

Tabel 2 Uji Asumsi Klasik

\begin{tabular}{ccc}
\hline \multicolumn{3}{c}{ One-Sample Kolmogorov-Smirnov Test } \\
\hline \multicolumn{1}{c}{$\mathrm{N}$} & \multicolumn{1}{c}{ Unstandardized Residual } \\
\hline \multirow{2}{*}{ Normal Parametersa,b } & Mean & 393 \\
\cline { 2 - 3 } & Std. Deviation & 0,0000000 \\
\hline \multirow{2}{*}{ Most Extreme Differences } & Absolute & 1,21734708 \\
\cline { 2 - 3 } & Positive & 0,044 \\
\cline { 2 - 3 } Test Statistic & 0,040 \\
\hline Asymp. Sig. (2-tailed) & $-0,044$ \\
\hline \multicolumn{3}{c}{ a. Test distribution is Normal. } \\
\hline \multicolumn{3}{c}{ b. Calculated from data. } \\
\hline \multicolumn{3}{c}{ c.Lilliefors Significance Correction. } \\
Sumber : Hasil Olahan Data SPSS 26 \\
\hline
\end{tabular}

Dari hasil pengujian di atas, diperoleh hasil sebagai berikut:

a) Jika Kolmogorov-Smirnov hitung $(0,044)<$ Kolmogorov-Smirnov tabel $(0,069)$, maka $\mathrm{H}_{0}$ diterima (data berdistribusi normal).

b) Nilai signifikansi sebesar 0,064 > 0,05, maka dapat dikatakan bahwa data tersebut berdistribusi normal.

\section{Uji Heteroskedastisitas}


Rahmi Hermawati, Rima Handayani \& Eni Puji Astuti, Analisis Pengaruh Pendidikan Karakter, Status

\begin{tabular}{|c|c|c|c|c|c|c|}
\hline \multicolumn{7}{|c|}{$\begin{array}{c}\text { Tabel } 3 \text { Uji Asumsi Klasik } \\
\text { Coefficientsa }\end{array}$} \\
\hline & \multirow[b]{2}{*}{ Model } & \multicolumn{2}{|c|}{ Unstandardized Coefficients } & \multirow{2}{*}{$\begin{array}{c}\text { Standardized Coefficients } \\
\text { Beta }\end{array}$} & \multirow[b]{2}{*}{$\mathrm{T}$} & \multirow[b]{2}{*}{ Sig. } \\
\hline & & $\mathrm{B}$ & Std. Error & & & \\
\hline \multirow[t]{4}{*}{1} & (Constant) & 1.711 & .268 & & 6.377 & .000 \\
\hline & Pendidikan Karakter & .000 & .007 & .005 & .073 & .942 \\
\hline & Status Sosial & -.015 & .026 & -.050 & -.577 & .564 \\
\hline & Jiwa Humanis & -.043 & .023 & -.145 & -1.857 & .064 \\
\hline
\end{tabular}

Tabel 4. a. Dependent Variable: ABS_RES1

\begin{tabular}{|c|c|c|c|}
\hline Variabel Bebas & r & signifikansi & Keterangan \\
\hline Pendidikan Karakter & 0,942 & 0,05 & Homokedastisitas \\
\hline Disiplin & 0,564 & 0,05 & Homokedastisitas \\
\hline Motivasi & 0,064 & 0,05 & Homokedastisitas \\
\hline
\end{tabular}

Sumber : Data Primer yang telah diolah (2020)

Dari tabel di atas, dapat dilihat signifikansi hasil korelasi lebih besar $(0,942 ; 0,564$; dan $0,064)$ dari 0,05 (5\%) maka persamaan regresi tersebut tidak mengandung heteroskedastisitas atau homokedastisitas, sehingga dapat disimpulkan bahwa pada model regresi ini tidak terjadi masalah heteroskedastisitas.

\section{Uji Multikolinearitas}

Tabel 5 Uji Multikolinieritas

\section{Coefficients $^{\mathrm{a}}$}

\begin{tabular}{|c|c|c|c|c|c|c|c|c|}
\hline & \multirow[t]{2}{*}{ Model } & \multicolumn{2}{|c|}{ Unstandardized Coefficients } & \multirow{2}{*}{$\begin{array}{c}\begin{array}{c}\text { Standardized } \\
\text { Coefficients }\end{array} \\
\text { Beta } \\
\end{array}$} & \multirow[t]{2}{*}{$\mathrm{t}$} & \multirow[t]{2}{*}{ Sig. } & \multicolumn{2}{|c|}{ Collinearity Statistics } \\
\hline & & $\mathrm{B}$ & Std. Error & & & & Tolerance & VIF \\
\hline \multirow[t]{4}{*}{1} & (Constant) & $-4,061$ & 0,484 & & $-8,398$ & 0,000 & & \\
\hline & $\begin{array}{c}\text { Pendidikan } \\
\text { Karakter }\end{array}$ & 0,134 & 0,012 & 0,471 & 10,919 & 0,000 & 0,457 & 2,186 \\
\hline & Status Sosial & 0,077 & 0,047 & 0,083 & 1,647 & 0,100 & 0,335 & 2,984 \\
\hline & Jiwa Humanis & 0,323 & 0,042 & 0,352 & 7,675 & 0,000 & 0,405 & 2,467 \\
\hline
\end{tabular}

\section{a. Dependent Variable: Budaya K3}

Sumber : Data Primer yang diolah (2020)

Dari data tabel di atas dapat diketahui bahwa syarat untuk lolos dari uji multikolinieritas sudah terpenuhi oleh seluruh variabel independen yang ada, yaitu nilai tolerance yang tidak kurang dari 0,10 dan nilai VIF (Variance Inflation Factor) yang tidak lebih dari 10, maka dapat disimpulkan bahwa seluruh variabel independen yang digunakan dalam penelitian ini tidak berkorelasi antara variabel independen satu dengan variabel independen lainnya.

\section{b. Uji Regresi Linier Berganda}

Tabel 6 Uji Regresi Linier Berganda

\begin{tabular}{|c|c|c|c|c|c|c|}
\hline \multicolumn{2}{|l|}{ Model } & \multicolumn{2}{|c|}{$\begin{array}{l}\text { Unstandardized } \\
\text { Coefficients }\end{array}$} & \multirow{2}{*}{\begin{tabular}{|c|}
$\begin{array}{c}\text { Standardiz } \\
\text { ed } \\
\text { Coefficient } \\
\text { s }\end{array}$ \\
Beta \\
\end{tabular}} & \multirow[t]{2}{*}{$\mathrm{t}$} & \multirow[t]{2}{*}{ Sig. } \\
\hline & & $B$ & Std. Error & & & \\
\hline \multirow{4}{*}{1} & (Constant) & $-4,061$ & 0,484 & & $-8,398$ & 0,000 \\
\hline & Pendidikan Karakter & 0,134 & 0,012 & 0,471 & 10,919 & 0,000 \\
\hline & Status Sosial & 0,077 & 0,047 & 0,083 & 1,647 & 0,100 \\
\hline & Jiwa Humanis & 0,323 & 0,042 & 0,352 & 7,675 & 0,000 \\
\hline
\end{tabular}

Sumber : Data Primer yang diolah (2020) 
Dari hasil perhitungan pada tabel di atas, dapat disajikan ke dalam bentuk persamaan regresi sebagai berikut :

$$
\begin{aligned}
& Y=-4.061+\mathbf{0 , 1 3 4} \mathbf{X}_{\mathbf{1}}+\mathbf{0 , 0 7 7} \mathrm{X}_{2}+\mathbf{0 , 3 2 3} \mathbf{X}_{\mathbf{3}} \\
& \text { Di mana: } Y=\text { Budaya K3 } \\
& \mathrm{X}_{1}=\text { Varibel Pendidikan Karakter } \\
& \mathrm{X}_{2}=\text { Variabel Status Sosial } \\
& \mathrm{X}_{3}=\text { Variabel Jiwa Humanis }
\end{aligned}
$$

Hasil persamaan regresi berganda tersebut dapat dilihat bahwa koefisien regresi yang diperoleh bertanda positif. Hal tersebut menunjukkan bahwa variabel pendidikan karakter, status sosial, dan jiwa humanis mempunyai pengaruh positif terhadap budaya K3.

Adapun persamaan tersebut dapat dijelaskan sebagai berikut:

1) Konstanta sebesar $\mathbf{- 4 , 0 6 1}$ menyatakan bahwa tanpa variabel pendidikan karakter, status sosial, dan jiwa humanis besarnya nilai budaya K3 tetap terbentuk -4,061.

2) Variabel pendidikan karakter $\left(\mathrm{X}_{1}\right)$ berpengaruh positif terhadap budaya $\mathrm{K} 3(\mathrm{Y})$ dengan nilai koefisien sebesar $\mathbf{0 , 1 3 4}$. Yang artinya jika variabel pendidikan karakter $\left(\mathrm{X}_{1}\right)$ meningkat satu satuan dengan asumsi variabel status sosial $\left(\mathrm{X}_{2}\right)$ dan jiwa humanis $\left(\mathrm{X}_{3}\right)$ bernilai tetap, maka kinerja karyawan akan meningkat sebesar 0,134.

3) Variabel Status Sosial $\left(\mathrm{X}_{2}\right)$ berpengaruh positif terhadap kinerja budaya K3 (Y) dengan nilai koefisien sebesar $\mathbf{0 , 0 7 7}$. Yang artinya jika variabel status sosial $\left(\mathrm{X}_{2}\right)$ meningkat satu satuan dengan asumsi variabel pendidikan karakter $\left(\mathrm{X}_{1}\right)$ jiwa humanis $\left(\mathrm{X}_{3}\right)$ bernilai tetap, maka budaya K3 akan meningkat sebesar 0,077.

4) Variabel jiwa humanis $\left(\mathrm{X}_{3}\right)$ berpengaruh positif terhadap budaya $\mathrm{K} 3(\mathrm{Y})$ dengan nilai koefisien sebesar $\mathbf{0 , 3 2 3}$. Yang artinya jika variabel jiwa humanis $\left(\mathrm{X}_{3}\right)$ meningkat satu satuan dengan asumsi variabel pendidikan karakter $\left(\mathrm{X}_{1}\right)$ dan jiwa humanis $\left(\mathrm{X}_{2}\right)$ bernilai tetap, maka budaya K3 akan meningkat sebesar 0,323.

\section{c. Uji Hipotesis}

\section{Uji Koefisien Determinasi}

Tabel 7 Uji Koefiisen Determinasi

\begin{tabular}{|lr|r|r|c|}
\hline \multicolumn{5}{|c|}{ Model Summary } \\
\hline Model & R & R Square & $\begin{array}{c}\text { Adjusted R } \\
\text { Square }\end{array}$ & $\begin{array}{c}\text { Std. Error of the } \\
\text { Estimate }\end{array}$ \\
\hline 1 & $.182^{3}$ & 0,033 & 0,026 & 0,67809 \\
\hline
\end{tabular}

a. Predictors: (Constant), Jiwa Humanis, Pendidikan Karakter, Status Sosial

Sumber : Data Primer yang diolah (2020)

Berdasarkan hasil uji koefisien determinasi pada tabel model summary diatas, besarnya nilai pengaruh variabel bebas ditunjukan oleh nilai $\mathrm{R}$ square $=0,033$ maka $\left(\mathrm{KD}=\mathrm{r}^{2}\right) \times 100 \%=0,033 \mathrm{x}$ $100 \%=3,3 \%$ ), jadi dapat disimpulkan bahwa Pendidikan Karakter $\left(\mathrm{X}_{1}\right)$, Status Sosial $\left(\mathrm{X}_{2}\right)$, dan Jiwa Humanis $\left(X_{3}\right)$ memberikan kontribusi sebesar 3,3\% terhadap Budaya K3, sedangkan 96,7\% oleh variabel lain yang tidak diteliti didalam penelitian ini.

\section{Uji T (Parsial)}

Tabel 8 Uji T $\left(\mathrm{X}_{1}, \mathrm{Y}\right)$ 
Rahmi Hermawati, Rima Handayani \& Eni Puji Astuti, Analisis Pengaruh Pendidikan Karakter, Status

\begin{tabular}{|l|l|c|r|r|}
\hline Model & & $\begin{array}{c}\text { Unstandardized } \\
\text { Coefficients }\end{array}$ & \multicolumn{1}{c|}{$\mathrm{t}$} & Sig. \\
\hline & & $\mathrm{B}$ & & \\
\hline 1 & (Constant) & $-3,724$ & $-6,851$ & 0,000 \\
\hline & Pendidikan Karakter & 0,216 & 23,038 & 0,000 \\
\hline
\end{tabular}
a. Dependent Variable: Budaya K3

Sumber : Data Primer yang diolah (2020)

Hasil perhitungan pada tabel di atas, dapat dijelaskan sebagai berikut: Uji $t$ terhadap variabel Kompensasi $\left(\mathrm{X}_{1}\right)$ diperoleh $\mathrm{t}_{\text {hitung }}$ sebesar 23,038 dengan signifikansi sebesar 0,000.

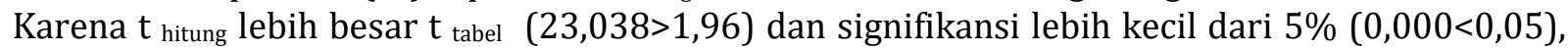
maka secara parsial variabel Pendidikan Karakter $\left(\mathrm{X}_{1}\right)$ berpengaruh positif dan signifikan terhadap variabel Budaya K3 (Y).

Tabel 9 Uji T $\left(\mathrm{X}_{2}, \mathrm{Y}\right)$

\begin{tabular}{|l|l|c|r|r|}
\hline Model & & $\begin{array}{c}\text { Unstandardized } \\
\text { Coefficients }\end{array}$ & \multicolumn{1}{c|}{$\mathrm{t}$} & \multicolumn{1}{c|}{ Sig. } \\
\hline & & $\mathrm{B}$ & & \\
\hline 1 & (Constant) & 0,502 & 1,135 & 0,257 \\
\hline & Status Sosial & 0,641 & 18,806 & 0,000 \\
\hline
\end{tabular}
a. Dependent Variable: Budaya K3

Sumber : Data Primer yang diolah (2020)

Hasil perhitungan pada tabel di atas, dapat dijelaskan sebagai berikut: Uji t terhadap variabel status sosial $\left(\mathrm{X}_{2}\right)$ diperoleh $\mathrm{t}_{\text {hitung }}$ sebesar 18,806 dengan signifikansi sebesar 0,000.

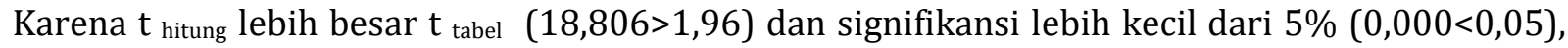
maka secara parsial variabel status sosial $\left(\mathrm{X}_{2}\right)$ berpengaruh positif dan signifikan terhadap variabel budaya K3 (Y).

Tabel 10 Uji T $\left(\mathrm{X}_{1}, \mathrm{Y}\right)$

\begin{tabular}{|l|l|c|r|r|}
\hline Coefficients & \\
\hline Model & & $\begin{array}{c}\text { Unstandardized } \\
\text { Coefficients }\end{array}$ & \multicolumn{1}{c|}{$\mathrm{t}$} & \multicolumn{1}{c|}{ Sig. } \\
\hline & & $\mathrm{B}$ & & \\
\hline 1 & (Constant) & 0,410 & 0,997 & 0,319 \\
\hline & Jiwa Humanis & 0,660 & 20,494 & 0,000 \\
\hline
\end{tabular}

a. Dependent Variable: Budaya K3

Sumber : Data Primer yang diolah (2020)

Hasil perhitungan pada tabel 4.17 di atas, dapat dijelaskan sebagai berikut: Uji t terhadap variabel jiwa humanis $\left(\mathrm{X}_{3}\right)$ diperoleh $\mathrm{t}_{\text {hitung }}$ sebesar 20,494 dengan signifikansi sebesar 0,000. Karena $t_{\text {hitung }}$ lebih besar $t_{\text {tabel }}(20,494>1,96)$ dan signifikansi lebih kecil dari $5 \%(0,000<0,05)$, maka secara parsial variabel jiwa humanis $\left(\mathrm{X}_{3}\right)$ berpengaruh positif dan signifikan terhadap variabel budaya $\mathrm{K} 3(\mathrm{Y})$.

Uji F (Simultan)

Tabel 11 Uji $F\left(X_{1}, X_{2}, X_{3}\right.$ dan $\left.Y\right)$ 
Vol 3, No. 2, Desember 2020: 610 -619, DOI: https://doi.org/10.34007/iehss.v3i2.376

\begin{tabular}{|c|c|c|c|c|c|c|}
\hline \multicolumn{7}{|c|}{ ANOVA $^{a}$} \\
\hline Model & & Sum of Squares & df & $\begin{array}{l}\text { Ivearl } \\
\text { Square }\end{array}$ & $\mathrm{F}$ & Sig. \\
\hline 1 & Regressio & 1170,441 & 3 & 390,147 & 261,254 & $.000^{\mathrm{t}}$ \\
\hline & Residual & 580,918 & 389 & 1,493 & & \\
\hline & Total & 1751,359 & 392 & & & \\
\hline
\end{tabular}

Sumber : Data yang diolah (2020)

Dari tabel di atas, dapat diperoleh melalui hasil IBM SPSS (Statistical Program for Social Science) versi 26.00 for windows ini berarti, uji hipotesis secara simultan yaitu untuk menguji seberapa besar pengaruh secara bersama-sama variabel bebas terhadap variabel terikat

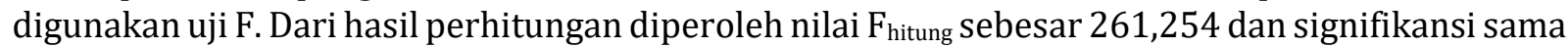
dengan 0,000. Jadi $F_{\text {hitung }}>F_{\text {tabel }},(261,254>2,62)$ dan signifikansi lebih kecil dari $5 \%(0,000<$ $0,05)$. Artinya bahwa secara bersama-sama variabel bebas yang terdiri dari variabel pendidikan karakter $\left(\mathrm{X}_{1}\right)$, status sosial $\left(\mathrm{X}_{2}\right)$, dan jiwa humanis $\left(\mathrm{X}_{3}\right)$, berpengaruh positif dan signifikan terhadap variabel budaya K3 (Y), seperti tabel 4.18 di atas sebesar 0,33 (R Square).

Jadi hipotesis yang diajukan peneliti pada Bab II diterima, yaitu "Pengaruh Pendidikan Karakter, Status Sosial, dan Jiwa Humanis terhadap Budaya K3".

\section{SIMPULAN}

Secara parsial variabel pendidikan karkater $\left(\mathrm{X}_{1}\right)$ berpengaruh secara kuat, positif dan sangat signifikan terhadap variabel Kinerja $(Y)$ dengan nilai $t_{\text {hitung }}(23,038)>t_{\text {tabel }}(1,96)$ dan signifikansi lebih kecil dari 5\% $(0,000<0,05)$. Diperoleh hasil uji persamaan regresi : $\mathbf{Y}=\mathbf{- 3 , 7 2 4}+\mathbf{0 , 2 1 6} \mathbf{X}_{\mathbf{1}}$. Nilai R (korelasi) adalah 0,759 dan nilai $\mathrm{R}$ Square (determinasi) adalah 0,576, menunjukkan bahwa variabel Y (budaya K3) dipengaruhi oleh variabel $\mathrm{X}_{1}$ (pendidikan karakter) sebesar 57,6\% dan sisanya sebesar $42,4 \%$ dipengaruhi oleh faktor-faktor lain yang tidak diteliti.

Secara parsial variabel status sosial $\left(\mathrm{X}_{2}\right)$ berpengaruh secara kuat, positif dan signifikan terhadap variabel budaya $\mathrm{K} 3(\mathrm{Y})$ dengan nilai $t$ hitung $(18.806)>t$ tabel $(1,96)$ dan signifikansi lebih kecil dari $5 \%(0,000<0,05)$. Diperoleh hasil uji persamaan regresi : $\mathbf{Y}=\mathbf{0 , 5 0 2}+\mathbf{0 , 6 4 1} \mathbf{X}_{2}$. Nilai $\mathrm{R}$ (korelasi) adalah 0,689 dan nilai $\mathrm{R}$ Square (determinasi) adalah 0,475, menunjukkan bahwa variabel $\mathrm{Y}$ (budaya $\mathrm{K} 3$ ) dipengaruhi oleh variabel $\mathrm{X}_{2}$ (status sosial) sebesar $47,5 \%$ dan sisanya sebesar 52,5\% dipengaruhi oleh faktor-faktor lain yang tidak diteliti.

Secara parsial variabel jiwa humanis $\left(\mathrm{X}_{3}\right)$ berpengaruh secara kuat, positif dan signifikan terhadap variabel budaya $\mathrm{K} 3(\mathrm{Y})$ dengan nilai $t$ hitung $(20,494)>t_{\text {tabel }}(1,96)$ dan signifikansi lebih kecil dari $5 \%(0,000<0,05)$. Diperoleh hasil uji persamaan regresi : $\mathbf{Y}=\mathbf{0 , 4 1 0}+\mathbf{0 , 6 6 0} \mathbf{X}_{3}$. Nilai $\mathrm{R}$ (korelasi) adalah 0,720 dan nilai $\mathrm{R}$ Square (determinasi) adalah 0,518, menunjukkan bahwa variabel $Y$ (budaya $\mathrm{K} 3$ ) dipengaruhi oleh variabel $\mathrm{X}_{3}$ (jiwa humanis) sebesar $51,8 \%$ dan sisanya sebesar $48,1 \%$ dipengaruhi oleh faktor-faktor lain yang tidak diteliti.

Dalam pengujian secara simultan dengan menggunakan uji $\mathrm{F}$ menunjukkan adanya pengaruh yang sangat signifikan variabel pendidikan karakter $\left(\mathrm{X}_{1}\right)$, variabel status sosial $\left(\mathrm{X}_{2}\right)$, dan variabel jiwa humanis $\left(\mathrm{X}_{3}\right)$ secara bersama-sama terhadap variabel budaya $\mathrm{K} 3(\mathrm{Y})$. Hal dibuktikan dengan nilai $F_{\text {hitung }}(261,254)>F_{\text {tabel }}(2,62)$ dan signifikansi lebih kecil dari $5 \%(0,000<0,05)$. Diperoleh hasil uji persamaan regresi berganda:

\section{$Y=-4,061+0,134 X_{1}+0,077 X_{2}+0,323 X_{3}$}

Berdasarkan hasil uji $\mathrm{F}$ secara bersama-sama diperoleh pula besarnya pengaruh perkembangan pendidikan karakter, status sosial dan jiwa humanis terhadap budaya K3. Dengan nilai $\mathrm{R}$ (korelasi) adalah 0,182 dan nilai $\mathrm{R}$ Square (determinasi) adalah 0,033, menunjukkan bahwa variabel $\mathrm{Y}$ (budaya K3) dipengaruhi oleh variabel $\mathrm{X}_{1}$ (pendidikan karakter), variabel $\mathrm{X}_{2}$ (status sosial), dan variabel $\mathrm{X}_{3}$ (jiwa humanis) secara bersama-sama, sebesar $3,3 \%$ dan sisanya sebesar $96,7 \%$ dipengaruhi oleh faktor-faktor lain yang tidak diteliti. 
Rahmi Hermawati, Rima Handayani \& Eni Puji Astuti, Analisis Pengaruh Pendidikan Karakter, Status

\section{DAFTAR PUSTAKA}

Amelia, W.R. (2016). Pengaruh Stres Kerja dan Lingkungan Kerja Terhadap Kinerja Karyawan Melalui Kepuasan Kerja Sebagai Variabel Intervening Pada PT. Pelabuhan Indoensia I (Persero). Jurnal Manajemen Sains, 473 -484

Haryati, E., Suharyanto, A. Hasmayni, B. \& Siregar, F.H. (2019). The Effect of Work Environment and Work Stress on Employee Performance at PT Aneka Gas Industri Tbk Research Article in Proceedings of the 2nd International Conference on Social Sciences and Interdisciplinary Studies (formerly ICCSSIS), ICCSIS 2019, 24-25 October 2019, Medan, North Sumatera, Indonesia

Indrawan, I., Wijoyo, H., \& Awom, L. L. (2020). PENGANTAR PENDIDIKAN BUDI PEKERTI ANAK PRA SEKOLAH.

Indrawan, I., Wijoyo, H., Suherman, \& Wiguna, I. M. A. (2020). MANAJEMEN PENDIDIKAN KARAKTER (M. Latif (ed.); PERTAMA). CV. PENA PERSADA.

Indrawan, I., Wijoyo, H., Winditya, H., Utama, I. W. B., Siregar, C., \& Suherman. (2020). FILSAFAT PENDIDIKAN MULTIKULTURAL-. 231.

Latief, A. Zati, M.R. \& Pribadi, K. (2018). Analisis Faktor Faktor Yang Mempengaruhi Kinerja Karyawan. JUPIIS: Jurnal Pendidikan Ilmu-ilmu Sosial, 10 (2): 167-172.

Latief, A., Nurlina, N., Medagri, E., \& Suharyanto, A. (2019). Pengaruh Manajemen Pengetahuan, Keterampilan dan Sikap terhadap Kinerja Karyawan. JUPIIS: Jurnal Pendidikan Ilmu-Ilmu Sosial, 11(2), 173-182. doi:https://doi.org/10.24114/jupiis.v11i2.12608

Mora, Z., Suharyanto, A., Yahya, M., (2020). Effect of Work Safety and Work Healthy Towards Employee's Productivity in PT. Sisirau Aceh Tamiang, Budapest International Research and Critics Institute, 3(2): 753-760.

Nainggolan, K., \& Parulian, T. (2018). Revitalizing Cooperative Human Resources: An Education and Perspective Analysis, Study at Medan Municipal City; Indonesia. International Journal of Scientific Research and Management (IJSRM). 6(03). 19-36.

Syardiansah, Latief, A., Daud, M.N., Windi, \& Suharyanto, A, (2020), The Effect of Job Satisfaction and Organizational Culture on Employee Performance of the Royal Hotel in East Aceh District, Budapest International Research and Critics Institute, 3(2): 849-857.

Wijoyo, H., Sunarsi, D., Indrawan, I., \& Cahyono, Y. (2020). MANAJEMEN PEMASARAN DI ERA GLOBALISASI (M. Prof. Dr. Ir. H. Anoesyirwan Moeins, MSi. (ed.)). CV. PENA PERSADA.

Winardi, J. (2006). Teori Organisasi \& Pengorganisasian. Teori Organisasi \& Pengorganisasian, 16, 1-20.

Undang-Undang RI No. 20 Tahun 2003, Tentang Sistem Pendidikan Nasional 